\title{
Prevalence of childhood obesity and overweight in Bangladesh: findings from a countrywide epidemiological study
}

Tania Bulbul ${ }^{*}$ and Mozammel Hoque ${ }^{2}$

\begin{abstract}
Background: Obesity has been declared an epidemic in many high income countries. In low income countries, the coexistence of obesity and underweight makes the situation more grievous. The priority is to explore the overall pictures of body weight status in low income countries and countries that are in transitional phase. Through this country wide cross sectional study we would like to capture the current body weight status among the school aged children, both in urban and rural areas in Bangladesh.
\end{abstract}

Methods: We conducted a countrywide cross sectional study, from June to September 2009. By random sampling, we selected 10,135 students from 6 to 15 years from both the urban and rural schools. We categorized the students into overweight, obese and underweight by using the values for age and sex at +1SD, +2SD and -2 SD of Z scores of BMI respectively.

Results: We observed among 6 to 15 year olds from both the urban and rural areas 3.5\% were obese, 9.5\% were overweight and $17.6 \%$ were underweight. The proportion of obese and overweight students were greater among the students from urban schools $(5.6 \%, 10.6 \%)$ compared to the students from rural schools $(1.2 \%, 8.6 \%)(R D=4.3$, $95 \% \mathrm{Cl}=3.6,5.0 ; \mathrm{RD}=2.0,95 \% \mathrm{Cl}=0.1,3.1)$. The proportion of underweight students were lower in the urban schools (16.1\%) compared to the rural schools (19.2\%) $(\mathrm{RD}=-3.1 ; 95 \% \mathrm{Cl}=-4.6,-1.6)$

Conclusions: The rate of obesity and overweight is alarming among school aged children in Bangladesh. Overweight and underweight are coexisting which needs special attention to minimize the dual burden.

\section{Background}

The prevalence of obesity is very high in high income countries and many of them have declared obesity an epidemic $[1,2]$. In the US, obesity is considered a major health problem. Half the population is obese; among adults more than $60 \%$ are overweight and more than $30 \%$ are obese; among children over $17 \%$ are obese $[3,4]$. In the UK, among adults $23 \%$ of men and $25 \%$ of women are obese. Among children from 2 to 15 years $5.5 \%$ of boys and $7.2 \%$ of girls are obese and $22 \%$ of boys and $28 \%$ of girls are overweight [5].

The low income countries are showing the same trend as the high income countries in increasing rates of obesity. And the duel burden households are very common where

\footnotetext{
* Correspondence: dr.taniabulbul@gmail.com

${ }^{1}$ Center for Communicable Diseases, International Center for Diarrheal

Disease Research, Bangladesh, Dhaka, Bangladesh

Full list of author information is available at the end of the article
}

underweight and overweight coexist among the children [6]. Rapid urbanization and industrialization are changing the food habits resulting in socio-economic, demographic and cultural changes leading to nutritional transition in low income countries $[7,8]$.

To combat the burden of obesity different stakeholders have taken a variety of strategies to address diet, physical activity and health. Particularly for low-income countries or countries which are in a transitional phase, undernutrition is still prevalent, and control of obesity will be an additional burden [9].

The proportions of obesity among women in Bangladesh, and the related health and social problems has already been addressed in several studies $[10,11]$. However, there is a lack of national data for overall body weight status of school aged children. Through this country wide cross sectional study we would like to capture the current body 
weight status of school aged children both in urban and rural areas in Bangladesh.

\section{Methods}

We conducted a countrywide cross sectional study where we selected school aged children from 6 to 15 year olds from both the rural and urban schools in Bangladesh. We selected 10,135 students using random sampling method. First, we enrolled all six divisions that are the major administrative region of the country. Then we randomly selected two districts those are the second highest tier of regional administrative areas of the country from each division. In the district level we stratified the areas into urban and rural areas. The urban area, a pourasava (municipality) having such amenities as metalled roads, improved communication, electricity, gas, water supply, sewerage, sanitation, and also having higher density of population with majority population in non-agriculture occupations [12]. During selecting a rural area, we selected randomly a sub-district from the selected district (second lowest tier of regional administration). Then from each sub-district we selected a union (the lowest tier of regional administration) randomly.

From each selected union in rural area and municipality in urban area we selected one primary school and one secondary school randomly. Thus in total, we enrolled 48 schools where 24 were primary schools and 24 were secondary schools from 12 urban and 12 rural areas of 12 districts of the country. Based on a previous cross sectional study considered the prevalence of childhood obesity would be close to $7.6 \%$ [13]. At the 95\% significance level and with $90 \%$ power, we would require to enroll 4,007 students. As we enrolled all the students of the selected school, to account for the similarity among the students our estimated sample size was 8,014 would be sufficient considering the design effect of 2 [14]. We collected data from June to September 2009. 36 field workers were recruited and trained to take the body weight and height of the children. A team of three field workers in each school measured the body weight and height of the children at the school premises. The field worker calibrated the weight machine by applying a random set of the standard weights daily to roughly check the accuracy of the weight scales. While measuring the weight the children were asked to put off their shoes. Randomly five boys and five girls from each class from each school were selected to take weight of their school uniform separately and calculated the mean weight of the school uniform by sex. Then we calculated the actual body weight by deducting the mean weight of school uniform from their measured body weight. For taking the height we locally built a stadiometer and checked the horizontal bar was firmly attached with the sliding section before taking the measurement. While taking the height the children were asked to stand straight on bare foot and to look straight in front.

We excluded the child from the study if the child had been suffering from any mental or physical disability or the child was foreigner or from other ethnic minority group. We collected anthropometric measurement (body height and weight) of all the students from the selected schools met the inclusion criteria. We calculated BMI (Body Mass Index) and according to BMI we categorized students into normal weight if BMI was between overweight and underweight with respect to age and sex, overweight if BMI was more than the standardized value for age and sex at +1SD of Z scores of BMI, obese if $B M I$ was more than the standardized value for age and sex at +2SD of Z scores of BMI and underweight if BMI was more than the standardized value for age and sex at -2SD of Z scores of BMI [15].

After getting the approval from Institutional Review Board for the study, the ethical clearance had been obtained from the Ethical Clearance Committee of Bangabandhu Sheikh Mujib Medical University prior data collection. We informed the parents the day before data collection through a letter from the principal that all the students in the school would be interviewed and their height and weight would be measured to check their nutritional status for a study purpose. We obtained informed written consent from the principal or principal nominated teacher where principal was absent. All the students were thoroughly appraised about the nature, purpose and implications of the study and were also assured about their confidentiality and freedom to withdraw themselves from the study any time. All the data were recorded systematically in a preformed data collection sheet. Data were analyzed by using STATA. We described baseline characteristics (age groups, sex). We calculated the proportions of body weight status of the students with 95\% confidence intervals. To compare the body weight status among boys and girls, among the students from primary and secondary schools and among the students from urban and rural schools we calculated risk differences with 95\% confidence intervals.

\section{Results}

We enrolled total 10,135 students; among them 4,765 students were from rural schools and 5,370 students were from urban schools. In both urban and rural schools the distribution of boys and girls in primary and secondary schools were almost similar (Table 1).

This study revealed among 6 to 15 year olds from both the rural and urban areas $3.5 \%(95 \% \mathrm{CI}=3.0,4.0)$ were obese, $9.5 \%(95 \% \mathrm{CI}=9.0,10.0)$ were overweight and $17.6 \%(95 \% \mathrm{CI}=16.0,18.0)$ were underweight (Table 2).

We observed, the proportion of obese students were greater among the students from urban schools (5.6\%) 
Table 1 Baseline characteristics of the enrolled students

\begin{tabular}{lccccc}
\hline & \multicolumn{2}{c}{ Rural $(\mathbf{N}=\mathbf{4 7 6 5})$} & & Urban $(\mathbf{N}=\mathbf{5 3 7 0})$ \\
\cline { 2 - 3 } Total students $\mathbf{N}=\mathbf{1 0 , 1 3 5}$ & $\mathbf{n} / \mathbf{N}^{*}$ & $\%$ & & $\mathbf{n} / \mathbf{N}^{*}$ & $\%$ \\
\hline Students from Primary schools & & & & \\
(age: 6 to 10 years) $(\mathrm{N}=4555)$ & $2223 / 4765$ & 47 & & $2332 / 5370$ & 43 \\
$\quad$ Boys & $1071 / 2223$ & 48 & $1229 / 2332$ & 53 \\
$\quad$ Girls & $1152 / 2223$ & 51 & $1103 / 2332$ & 47 \\
Students from secondary schools & & & & \\
(age: 11 to 15 years) $(\mathrm{N}=5560)$ & $2542 / 4765$ & 53 & $3038 / 5370$ & 57 \\
$\quad$ Boys & $1229 / 2542$ & 48 & $1698 / 3038$ & 56 \\
Girls & $1313 / 2542$ & 52 & $1340 / 3038$ & 44 \\
\hline
\end{tabular}

${ }^{*} \mathrm{n}=$ number of subjects with indicator, $\mathrm{N}=$ Total number of subjects.

compared to the students from rural schools (1.2\%) $(\mathrm{RD}=$ 4.3; $95 \% \mathrm{CI}=3.6,5.0)$. More students from the urban schools $(10.6 \%)$ were overweight than the students from rural schools $(8.6 \%)(\mathrm{RD}=2.0 ; 95 \% \mathrm{CI}=0.1,3.1)$. However, the study revealed the proportion of underweight students was lower in the urban schools $(16.1 \%)$ compared to the rural schools $(19.2 \%)(\mathrm{RD}=-3.1 ; 95 \% \mathrm{CI}=-4.6,-1.6)$ (Table 3).

While comparing the students by area, among the boys the proportion of obesity was significantly higher in urban schools $(5.6 \%)$ compared to rural schools $(1.5 \%)(\mathrm{RD}=4$; $95 \% \mathrm{CI}=3$, 5). Similarly among the girls the proportions of both obesity and overweight were significantly higher in urban schools $(5.5 \%, 11.1 \%)$ compared to rural schools $(1.0 \%, 3.8 \%)(\mathrm{RD}=7 ; 95 \% \mathrm{CI}=6,9)$. However, among the girls the proportion of underweight was significantly lower in urban schools $(12.3 \%)$ compared to rural schools $(18.5 \%)(\mathrm{RD}=-6 ; 95 \% \mathrm{CI}=-8,-4)$ (Table 4$)$.

While comparing the students by sex, the proportion of overweight among boys (11.7\%) was higher compared to girls $(7.4 \%)(\mathrm{RD}=4.3 ; 95 \% \mathrm{CI}=3.1,5.4)$. The proportion of underweight among boys (19.6\%) was higher compared to girls $(15.4 \%)(\mathrm{RD}=4.1 ; 95 \% \mathrm{CI}=2.6,5.6)$. Among the girls, the proportion of obesity was significantly lower among 11 to 15 years olds (3.8\%) compared to 6 to 10 year olds $(2.8 \%)(\mathrm{RD}=-1.1 ; 95 \% \mathrm{CI}=-0.2,-0.1)$. Among the boys, the proportion of obesity was higher among 11 to 15 year olds (16.1\%) compared to 6 to 10 year olds $(6.1 \%)$ $(\mathrm{RD}=9.9 ; 95 \% \mathrm{CI}=8.2,11.7)$. Among both the boys and girls, the proportion of underweight was significantly

Table 2 Prevalence of obesity, overweight and underweight among study subjects

\begin{tabular}{llll}
\hline Indicators & $\mathbf{n} / \mathbf{N}^{*}=\mathbf{1 0 1 3 5}$ & $\mathbf{\%}$ & $\mathbf{9 5 \%}$ Confidence interval \\
\hline Obese & 359 & 3.5 & $(3,4)$ \\
Overweight & 977 & 9.6 & $(9,10)$ \\
Underweight & 1780 & 17.6 & $(16,18)$ \\
\hline
\end{tabular}

${ }^{*} \mathrm{n}=$ number of subjects with indicator, $\mathrm{N}=$ Total number of subjects. lower among 11 to 15 year olds (10.1\%) compared to 6 to 10 year olds $(21.8 \%)(\mathrm{RD}=-11.795 \% \mathrm{CI}=-13.7,-9.7)$ (Table 5).

\section{Discussion}

The prevalence of obesity and overweight among Bangladeshi school children of 6 to 15 year olds found $3.5 \%$ and $9.7 \%$ respectively. The available data from the other South East Asian showed the similar rate of obesity among school aged children [16]. Among the Saudi children from 6 to 18 year olds the prevalence of obesity and overweight was around $6 \%$ and $12 \%$ respectively [17]. Though the rate of obesity is higher in high income countries, the rate of obesity is also increasing in low income countries. Most studies from the high income countries reported an increasing prevalence of obesity in childhood and adolescence period [18]. However, in Thailand, obesity among 6 to 12 year olds increased from $12.2 \%$ to $15.6 \%$ in two years, between 1991 and 1993 [19]. A recent cross sectional study conducted in Dhaka city among 5000 study subjects identified 380 children (7.6\%) were obese [13]. The proportion of obesity from this previous study was much higher probably due to smaller sample size and also they enrolled a subgroup of population from a metropolitan city in contrast to our countrywide sampling.

There is good evidence that the rate of childhood obesity is increasing in low and middle income countries. Malnutrition and obesity coexist in many low income countries. According to a review article, obesity does not appear to be public health problem among school children in Asia and sub-Saharan Africa. However, many countries in Latin America, Caribbean, Middle East, North Africa, central/Eastern Europe and the common wealth of independent states, the proportions of obesity among children are as high as they are in United States $[7,20]$. Considering the large differences in sociocultural contexts of these countries and rapidity of the epidemiologic transition, the extent of childhood obesity and overweight largely differs across countries [2].

Our study revealed high level of underweight (17.6\%) among 6 to 15 year olds. An analysis of 160 nationally representative surveys from 94 low income countries showed an increasing rate of overweight and obesity among the obese children from childhood to adulthood, although rates of early childhood malnutrition remained relatively high. Certain countries demonstrated high prevalence of overweight in conjunction with high frequencies of malnutrition. In northern Africa, the proportion of overweight children exceeded $8 \%$ and that of children with wasting exceeded $7 \%$. Similarly in south east-Asia, $2.4 \%$ of preschool children are overweight and $10.4 \%$ suffers from wasting [21]. However, another review article with based on nationally representative data from Brazil, China, United States of America and 
Table 3 Body weight status among primary and secondary schools students in urban and rural areas

\begin{tabular}{|c|c|c|c|c|c|c|c|c|c|}
\hline & \multicolumn{4}{|c|}{ Urban } & \multicolumn{4}{|c|}{ Rural } & \multirow[b]{2}{*}{$\begin{array}{l}\text { Comparison between } \\
\text { students from urban } \\
\text { and rural areas }\end{array}$} \\
\hline & $\begin{array}{l}\text { Total number } \\
\text { of students }\end{array}$ & $\begin{array}{l}\text { Primary school } \\
\text { students } \\
\text { (6 to } 10 \text { years) }\end{array}$ & $\begin{array}{l}\text { Secondary school } \\
\text { students } \\
\text { (11 to } 15 \text { years) }\end{array}$ & $\begin{array}{l}\text { Comparison between } \\
\text { primary and } \\
\text { secondary students }\end{array}$ & $\begin{array}{l}\text { Total number } \\
\text { of students }\end{array}$ & $\begin{array}{l}\text { Primary school } \\
\text { students } \\
\text { (6 to } 10 \text { years) }\end{array}$ & $\begin{array}{c}\text { Secondary } \\
\text { school students } \\
\text { (11 to } 15 \text { years) }\end{array}$ & $\begin{array}{c}\text { Comparison between } \\
\text { primary and } \\
\text { secondary students }\end{array}$ & \\
\hline Indicators & $N=5370 n(\%)^{*}$ & $\mathrm{~N}=2332 \mathrm{n}(\%)^{*}$ & $N=3038 n(\%)^{*}$ & $\mathrm{RD}(95 \% \mathrm{Cl})^{\dagger}$ & $N=4765 n(\%)^{*}$ & $N=2223 n(\%)^{*}$ & $\mathrm{~N}=2542 \mathrm{n}(\%)^{*}$ & $\mathrm{RD}(95 \% \mathrm{Cl})^{\dagger}$ & $\mathrm{RD}(95 \% \mathrm{Cl})^{\dagger}$ \\
\hline Obese & $300(5.6)$ & $173(7.4)$ & $127(4.2)$ & $-3.2(-4.4,-2.0)$ & $59(1.2)$ & $21(0.9)$ & $38(1.5)$ & $0.6(-0.1,1.2)$ & $4.3(3.6,5.0)$ \\
\hline Overweight & $597(10.6)$ & $234(10.0)$ & $333(11.0)$ & $1.0(-0.7,2.6)$ & 410 (8.6) & $60(2.7)$ & $350(13.8)$ & $11(9.5,12.6)$ & $2.0(0.1,3.1)$ \\
\hline Underweight & $865(16.1)$ & $453(19.4)$ & 412 (13.6) & $-5.9(-7.8,-3.9)$ & 915 (19.2) & $605(27.2)$ & $310(12.2)$ & $-15(-17.2,-12.8)$ & $-3.1(-4.6,-1.6)$ \\
\hline
\end{tabular}

${ }^{*} \mathrm{n}=$ number of subjects with indicator, $\mathrm{N}=$ Total number of subjects.
${ }^{+} \mathrm{RD}=$ Risk difference indicates the difference of proportions of indicators among the comparison groups. Positive sign (+) denotes, obesity/ overweight/underweight are more common among the children from urban ${ }^{\mathrm{RD}}=$ Risk difference indicates the difference of proportions of indicators among the comparison groups. Positive sign (+) denotes, obesity/ overweight/underweight are $\mathrm{m}$.
schools than the children from rural schools and more common among the children from secondary schools than the primary schools; negative sign (-) is less common. 


\section{Table 4 Body weight status among the boys and girls in urban and rural schools}

\begin{tabular}{|c|c|c|c|c|c|c|c|c|}
\hline & \multicolumn{3}{|c|}{ Urban schools } & \multicolumn{3}{|c|}{ Rural schools } & \multirow[b]{2}{*}{$\begin{array}{l}\text { Comparison among } \\
\text { boys between urban } \\
\text { and rural schools }\end{array}$} & \multirow[b]{2}{*}{$\begin{array}{l}\text { Comparison among } \\
\text { girls between urbar } \\
\text { and rural schools }\end{array}$} \\
\hline & Boys & Girls & $\begin{array}{c}\text { Comparison between } \\
\text { boys and girls }\end{array}$ & Boys & Girls & $\begin{array}{c}\text { Comparison between } \\
\text { boys and girls }\end{array}$ & & \\
\hline Indicators & $N=2927 n(\%)^{*}$ & $N=2443 n(\%)^{*}$ & $\mathrm{RD}(95 \% \mathrm{Cl})^{\dagger}$ & $N=2300 n(\%)^{*}$ & $N=2465 n(\%)^{*}$ & $\mathrm{RD}(95 \% \mathrm{Cl})^{\dagger}$ & $\mathrm{RD}(95 \% \mathrm{Cl})^{\dagger}$ & $\mathrm{RD}(95 \% \mathrm{Cl})^{+}$ \\
\hline Obese & $165(5.6)$ & $135(5.5)$ & $0.001(-0.01,0.01)$ & $35(1.5)$ & $24(1.0)$ & $0.01(-0.001,0.01)$ & $4(3,5)$ & $5(4,6)$ \\
\hline Overweight & $296(10.1)$ & $271(11.1)$ & $-0.01(-0.03,0.01)$ & $317(13.8)$ & $93(3.8)$ & $10(8.4,11.6)$ & $-4,(-5,-2)$ & $7(6,9)$ \\
\hline Underweight & 564 (19.3) & 301 (12.3) & $7(5,9)$ & 458 (19.9) & 457 (18.5) & $1(-0.01,0.04)$ & $-0.01(-3,2)$ & $-6(-8,-4)$ \\
\hline
\end{tabular}

${ }^{*} \mathrm{n}=$ number of subjects with indicator, $\mathrm{N}=$ Total number of subjects.

${ }^{+} \mathrm{RD}=$ Risk difference indicates the difference of proportions of indicators among the comparison groups. Positive sign (+) denotes, obesity/ overweight/underweight are more common among the children from urban schools than the children from rural schools and more common among the boys than the girls; negative sign (-) is less common. 
Table 5 Body weight status among the primary and secondary school students among boys and girls irrespective of area

\begin{tabular}{|c|c|c|c|c|c|c|c|c|c|}
\hline & \multicolumn{4}{|c|}{ Boys } & \multicolumn{4}{|c|}{ Girls } & \multirow[b]{2}{*}{$\begin{array}{c}\text { Comparison } \\
\text { between boys } \\
\text { and girls }\end{array}$} \\
\hline & $\begin{array}{l}\text { Total number } \\
\text { of boys }\end{array}$ & $\begin{array}{l}\text { Primary students } \\
\text { (6 to } 10 \text { years) }\end{array}$ & $\begin{array}{c}\text { Secondary } \\
\text { (11 to } 15 \text { years) }\end{array}$ & $\begin{array}{l}\text { Comparison among the } \\
\text { boys between primary } \\
\text { and secondary students }\end{array}$ & $\begin{array}{l}\text { Total number } \\
\text { of girls }\end{array}$ & $\begin{array}{l}\text { Primary students } \\
\text { (6 to } 10 \text { years) }\end{array}$ & $\begin{array}{l}\text { Secondary students } \\
\text { (11 to } 15 \text { years) }\end{array}$ & $\begin{array}{l}\text { Comparison among the } \\
\text { girls between primary } \\
\text { and secondary students }\end{array}$ & \\
\hline Indicators & $N=5227 n(\%)^{*}$ & $N=2300 n(\%)^{*}$ & $N=2927 n(\%)^{*}$ & $\mathrm{RD}(95 \% \mathrm{Cl})^{+}$ & $N=4908 n(\%)^{*}$ & $N=2255 n(\%)^{*}$ & $N=2653 n(\%)^{*}$ & $\mathrm{RD}(95 \% \mathrm{Cl})^{\dagger}$ & $\mathrm{RD}(95 \% \mathrm{Cl})^{\dagger}$ \\
\hline Obese & $200(3.8)$ & $108(4.7)$ & $92(3.1)$ & $-1.5(2.6,-0.5)$ & $159(3.2)$ & $86(3.8)$ & $73(2.8)$ & $-1.1(-0.2,-0.1)$ & $0.6(-0.1,1.3)$ \\
\hline Overweight & $613(11.7)$ & $141(6.1)$ & $472(16.1)$ & $9.9(8.2,11.7)$ & $364(7.4)$ & $153(6.8)$ & $211(8)$ & $1.2(-0.3,2.6)$ & $4.3(3.1,5.4)$ \\
\hline Underweight & $1022(19.6)$ & $567(24.7)$ & $455(15.5)$ & $-9.1(-11.2,-7.0)$ & $758(15.4)$ & $491(21.8)$ & $267(10.1)$ & $-11.7(-13.7,-9.7)$ & $4.1(2.6,5.6)$ \\
\hline
\end{tabular}

${ }^{*} \mathrm{n}=$ number of subjects with indicator, $\mathrm{N}=$ Total number of subjects.
${ }^{+} \mathrm{RD}=$ Risk difference indicates the difference of proportions of indicators among the comparison groups. Positive sign $(+)$ denotes, obesity/ overweight/underweight are more common among the boys than the girls ${ }^{\mathrm{R}} \mathrm{RD}=$ Risk difference indicates the difference of proportions of indicators among the comparison groups. Positive sign (+) denots
and more common among the children from secondary schools than the primary schools; negative sign (-) is less common. 
Russia showed the inverse relationship of co-existence of overweight and underweight [22].

This study revealed, more boys were both overweight and underweight compared to girls among 6 to 15 year olds. A cross sectional survey in Lebanon showed prevalence of childhood obesity much higher in boys (7.5\%) than the girls (3.2\%) among 3 to 19 year olds [23]. Another study on the Finish children observed greater rate of overweight and obesity among the boys than the girls [24]. In USA, boys were more at risk for overweight than the girls among 6 to 19 year olds [3]. However, the sex distribution varies among the ethnic groups. Another study in USA showed more girls were overweight and obese among the non-Hispanic black children than the boys among 12 to 19 year olds [25].

Compared to rural children among 6 to 15 year olds, the study revealed more children in the urban schools were overweight and obese. From a cross-sectional study was performed on 541 children (273 boys and 268 girls) aged 6-7 years, in urban and rural areas of South-East Serbia found more obese children in urban areas than the rural areas. This difference ascribed to more sweets and fast food consumption and spending time in watching TV among the urban children compared to rural children [26]. Another study in China showed that the rate of childhood obesity is more in urban children $(23-30 \%)$ than in rural children (16-20\%) and the difference was not only because of that the children in rural China are physically more active but also the reason is the urban children consume more fat than rural children. Urban children in China are engaged in more academic work because they are under pressure to achieve scholastic excellence, whereas rural Chinese children are engaged more in physical work to meet economic necessity [27].

Lower to middle income nations face double burden of having both malnourished and over nourished populations, where overweight and obese children being concentrated in urban areas mostly. In developing countries, the rapid progress of urbanization is associated with a cluster of non-communicable diseases and unhealthy lifestyles, which results in very high rates of obesity and its consequent morbidity and mortality. Moreover, in such communities, childhood obesity is still considered a sign of healthiness and high social class [28].

\section{Conclusions}

The prevalence of obesity and overweight is alarming among the school aged children in Bangladesh. While underweight is still predominating among the rural children, obesity and overweight prevailing among the urban children. To combat the future dual burden of communicable diseases and the non-communicable diseases as a consequence of underweight and overweight, we need to understand the social perspective of overweight and obesity in the low income countries in order to take appropriate measure by the government and other stakeholders.

\section{Competing interests}

The authors declare that they have no competing interests.

\section{Authors' contributions}

TB conceptualized, designed, analyzed data and wrote the manuscript. MH contributed in study design and writing. And also have given final approval of the version to be published. Both authors read and approved the final manuscript.

\section{Authors' information}

Tania Bulbul, MD, MPH, Assistant scientist, CCD, icddr,b, Dhaka, Bangladesh Dr. Md. Mozammel Hoque, Professor, Department of Biochemistry, Bangabandhu Sheikh Mujib Medical University, Dhaka, Bangladesh.

\section{Acknowledgements}

This study was supported by the University Grant Commission, Bangladesh. The authors thank all the data collectors, study participants and the headmasters of the selected schools for permitting to conduct the study.

\section{Author details}

${ }^{1}$ Center for Communicable Diseases, International Center for Diarrheal Disease Research, Bangladesh, Dhaka, Bangladesh. ${ }^{2}$ Departmet of Biochemistry, Bangabandhu Sheikh Mujib Medical University, Dhaka, Bangladesh.

Received: 7 September 2013 Accepted: 28 March 2014

Published: 1 April 2014

\section{References}

1. Hill JO, Peters JC: Environmental contributions to the obesity epidemic. Science 1998, 280(5368):1371-1374.

2. James PT, Leach R, Kalamara E, Shayeghi M: The worldwide obesity epidemic. Obes Res 2001, 9(S11):228S-233S.

3. Hedley AA, Ogden $C L$, Johnson $C L$, Carroll MD, Curtin LR, Flegal KM: Prevalence of overweight and obesity among US children, adolescents, and adults, 1999-2002. JAMA: J Am Med Assoc 2004, 291(23):2847-2850.

4. Ogden CL, Carroll MD, Kit BK, Flegal KM: Prevalence of obesity in the United States, 2009-2010. NCHS data brief, no 82. Hyattsville, MD: National Center for Health Statistics: US Department of Health and Human Services, Centers for Disease Control and Prevention, National Center for Health Statistics; 2012.

5. Rennie KL, Jebb SA: Prevalence of obesity in Great Britain. Obes Rev 2005, 6(1):11-12.

6. Doak CM, Adair LS, Bentley M, Monteiro C, Popkin BM: The dual burden household and the nutrition transition paradox. Int J Obes 2004, 29(1):129-136.

7. Monteiro CA, Conde WL, Popkin BM: The burden of disease from undernutrition and overnutrition in countries undergoing rapid nutrition transition: a view from Brazil. Information: Journal; 2004:94(3).

8. Popkin BM: The nutrition transition in lowâ€ income countries: an emerging crisis. Nutr Rev 1994, 52(9):285-298.

9. Chopra M, Galbraith S, Darnton-Hill I: A global response to a global problem: the epidemic of overnutrition. Bull World Health Organ 2002, 80(12):952-958.

10. Shafique S, Akhter N, Stallkamp G, de Pee S, Panagides D, Bloem MW: Trends of under-and overweight among rural and urban poor women indicate the double burden of malnutrition in Bangladesh. Int J Epidemiol 2007, 36(2):449-457.

11. Martorell R, Khan LK, Hughes ML, Grummer-Strawn LM: Obesity in women from developing countries. Eur J Clin Nutr 2000, 54(3):247-252.

12. Bbs: Statistical year book of Bangladesh. In Bangladesh Bureau of Statistics, Ministry of Planning. Dhaka, Bangladesh: Government of the People's Republic of Bangladesh; 2009.

13. Rahman IK SMM, Khaled MA, Bhuyan MAH, Harun-Ar-Rashid, Malek MA, aMRK: Prevalence and determinants of childhood obesity in Dhaka City. In ASCON, Volume 10. Edited by Chair PT, Ansari A, Islam MS, Khan MSI, Osinski P, Rabbani GH, Rahim MA, Roy SK. Dhaka, Bangladesh: icddr,b; 2002:161. 
14. Killip S, Mahfoud Z, Pearce K: What is an intracluster correlation coefficient? Crucial concepts for primary care researchers. Ann Fam Med 2004, 2(3):204-208

15. Onis M, Onyango AW, Borghi E, Siyam A, Nishida C, Siekmann J: Development of a WHO growth reference for school-aged children and adolescents. Bull World Health Organ 2007, 85(9):660-667.

16. Jafar TH, Qadri Z, Islam M, Hatcher J, Bhutta ZA, Chaturvedi N: Rise in childhood obesity with persistently high rates of undernutrition among urban school-aged Indo-Asian children. Arch Dis Child 2008, 93(5):373-378.

17. El-Hazmi MAF, Warsy AS: The prevalence of obesity and overweight in 1-18-year-old Saudi children. Ann Saudi Med 2002, 22(5/6):303-307.

18. Wang Y, Lobstein T: Worldwide trends in childhood overweight and obesity. Int J Pediatr Obes 2006, 1(1):11-25.

19. Mo-suwan L, Junjana C, Puetpaiboon A: Increasing obesity in school children in a transitional society and the effect of the weight control program. Southeast Asian J Trop Med Public Health 1993, 24(3):590.

20. Monteiro CA, Moura EC, Conde WL, Popkin BM: Socioeconomic status and obesity in adult populations of developing countries: a review. Bull World Health Organ 2004, 82(12):940-946.

21. De Onis M, Blossner M: Prevalence and trends of overweight among preschool children in developing countries. Am J Clin Nutr 2000, 72(4):1032-1039

22. Wang $Y$, Monteiro C, Popkin BM: Trends of obesity and underweight in older children and adolescents in the United States, Brazil, China, and Russia. Am J Clin Nutr 2002, 75(6):971-977.

23. Sibai AM, Hwalla N, Adra N, Rahal B: Prevalence and covariates of obesity in Lebanon: findings from the first epidemiological study. Obes Res 2003, 11(11):1353-1361.

24. Kautiainen S, Rimpela A, Vikat A, Virtanen SM: Secular trends in overweight and obesity among Finnish adolescents in 1977-1999. Int J Obes Relat Metab Disord: I Int Assoc Study Obes 2002, 26(4):544-552.

25. Ogden C, Carroll M: Prevalence of obesity among children and adolescents: United States, trends 1963-1965 through 2007-2008. Center Dis Control Prevent Natl Center Health Statistics 2010, $201(0): 1-5$.

26. Stojanovic D, Belojevic G: Prevalence of obesity among children aged 6-7 years in South-East Serbia. Obes Rev 2009, 10(3):262-264.

27. Cheng TO: Obesity in Chinese children. JRSM 2004, 97(5):254

28. Kelishadi R: Childhood overweight, obesity, and the metabolic syndrome in developing countries. Epidemiol Rev 2007, 29(1):62-76.

doi:10.1186/1471-2431-14-86

Cite this article as: Bulbul and Hoque: Prevalence of childhood obesity and overweight in Bangladesh: findings from a countrywide epidemiological study. BMC Pediatrics 2014 14:86.

\section{Submit your next manuscript to BioMed Central and take full advantage of:}

- Convenient online submission

- Thorough peer review

- No space constraints or color figure charges

- Immediate publication on acceptance

- Inclusion in PubMed, CAS, Scopus and Google Scholar

- Research which is freely available for redistribution 